\title{
From Classroom Teaching to Clinical Practice: Experiences of Senior Dental Students Regarding the Shortened Dental Arch Concept
}

\author{
Saadika B. Khan, B.Ch.D., P.D.D., M.Sc.; Usuf M.E. Chikte, B.Ch.D., M.Sc., D.H.S.M., \\ M.Dent., Ph.D.; Ridwaan Omar, B.D.S., LDSRCS, M.Sc., FRACDS, FDSRCSEd
}

Abstract: This study explored the barriers to a meaningful translation of didactic classroom instruction to clinical practice, using the shortened dental arch (SDA) concept as a case study. A combination of survey and individual and group interviews (a mixedmethods approach) was used to collect data related to the SDA. The cohort consisted of senior dental students and their clinical teachers at the University of the Western Cape, South Africa. The response rates were 100 percent for the students $(n=73)$ and 78 percent for the clinical teachers $(n=16)$. Triangulation was employed to eliminate bias and strengthen the reliability of the research. In the quantitative analysis, most students ( 81 percent) reported having heard about the SDA concept at the university, but their responses revealed an absence of clinical implementation. The students agreed that patients can function adequately with an SDA and agreed with presenting it as a treatment option to patients. In the qualitative analysis, a "change in the clinical requirements," "being empowered by exposing them to SDA literature," and "change in health policies" were recommended measures to increase implementation of the SDA approach clinically. The students were positive about the SDA as a treatment option, but the lack of adequate knowledge and encouragement in clinical implementation was a hindrance to its use.

Dr. Khan is Senior Lecturer, Department of Restorative Dentistry, University of the Western Cape, South Africa; Dr. Chikte is Professor, Department of Interdisciplinary Health Sciences, Stellenbosch University, South Africa; and Dr. Omar is Professor, Department of Prosthodontics, Kuwait University, Kuwait. Direct correspondence and requests for reprints to Dr. Saadika B. Khan, Department of Restorative Dentistry, University of the Western Cape, Private Bag X01, Tygerberg 7505, South Africa; skhan@uwc.ac.za.

Keywords: dental education, shortened dental arch, clinical education, clinical diagnostic reasoning, South Africa

Submitted for publication 4/17/13; accepted 9/24/13

$\mathrm{B}$ est available evidence is increasingly accepted as an essential guide for best clinical practice. ${ }^{1}$ The process begins in the classroom, and the implementation then needs to manifest in the clinical setting. Alongside this, dental schools are adopting a more patient-oriented approach in their clinical educational programs, ${ }^{1-3}$ which generally assumes there is continuity and coherence in implementing best evidence from classroom teaching to clinical practice. ${ }^{4-6}$ To what extent this translational learning outcome is realized has long absorbed educators and clinicians.

Among the many theories of learning, the constructivist paradigm is described as one that alludes to the role of students and the teacher in facilitating the learning of concepts. ${ }^{2,7,8}$ Studies have emphasized the significance of a student-centered teaching strategy, which encourages a deep approach to experiential learning and knowledge transfer, resulting in more effective conceptual understanding of content. ${ }^{2,4,7-12}$ Researchers refer to traditional forms of lecturing (which restricts learning largely to passive modes) as the least effective method of knowledge acquisition. ${ }^{2,13}$ Active learning of concepts occurs in clinical practice, and this needs to be a guided process, placing the focus on the role of clinical teachers to facilitate this deep approach to learning. ${ }^{1,10}$

Since effective learning of the clinical process, from decision making to implementation, depends on the quality of the clinical teaching, ${ }^{5,6,14}$ the choice of clinical teachers becomes crucial. They must have the ability to mediate the experiential learning of students, appropriately guide them to do what is best for the patient (i.e., adopting a patient-centered approach), and critically assess student performance. ${ }^{1-3,5-8,12,14}$ Kreuger et al. found that students "forget" theoretical information when commencing clinical practice and are subsequently unable to transfer concepts to different contexts. ${ }^{13}$ To ensure that any disjuncture between classroom and clinical practice is minimized or avoided is key. ${ }^{5,6}$

Assessment in module-based clinical curricula should include students' performance based on not only their understanding and clinical application of 
concepts but also the completion of predetermined clinical procedures. ${ }^{15}$ It has been noted that assessment drives learning, an assertion supported by the finding that students in clinical modules are apparently contented with mere completion of the predetermined clinical procedures. ${ }^{2,3,16}$ At the same time, entrenched institutional and traditional practices can impede the inclusion of newer clinical concepts that are based on best evidence. Such a situation can be regarded as ethically questionable. ${ }^{3,14,17}$

It would therefore seem that the nature of the alignment between two educational outcomes needs exploring: 1) the transfer of concepts from classroom instruction to clinical practice and 2) the clinical competence (i.e., readiness and ability) of dental students to prescribe evidence-based therapeutic solutions. For this study, we decided that the shortened dental arch (SDA) concept lends itself well to exploring these questions. The SDA concept is a clinical management approach that is compatible with the functional needs of many older, partially dentate individuals. With practitioners and institutions seeking clinical solutions for historically disadvantaged South African communities, the SDA seemed to be a logical choice for this study.

In this case study, the SDA approach was used to examine the extent to which the transference of theoretical concepts to clinical practice occurs amongst senior dental students. The classic SDA consists of twenty occluding anterior and premolar teeth and represents a functional approach to managing partially dentate middle-aged and elderly patients and sometimes young, high-risk patients. ${ }^{18}$ The reduced posterior arches ensure adequate chewing function, and research has shown the SDA concept to be a clinically beneficial treatment option, albeit within defined clinical conditions. ${ }^{1,15,18-29}$ From a socioeconomic point of view, the SDA approach offers the additional advantage of being a compelling primary health care measure relevant for many underprivileged groups, such as some of South Africa's communities. $^{29}$

Traditionally, removable partial dentures (RPDs) are used to restore functions deemed essential in partially dentate patients. ${ }^{18-21}$ The necessity for such an approach has long been questioned (more so in the context of limited resources), and evidence is ubiquitous that the profession still resists modifying traditional clinical practice accordingly. ${ }^{15,18,29-34}$ This apparent resistance to implementing the SDA approach in specific conditions can be related to several factors: an indifference towards including evidence-based findings in teaching and practice, utilizing practices based on tradition and peer input, misplaced confidence in traditional practices, the need to complete a procedure to satisfy patients, profit-based practices, the inadequacy of knowledge transfer to clinical practice, and/or a general disinclination of clinicians to apply new concepts. ${ }^{13,17}$

Although there have been attempts to change oral health care policies based on clinical research, ${ }^{15,18-28,30-33}$ there is a void on the subject of translation of classroom teaching to clinical implementation. The aim of this study was therefore to determine the relationship between what dental students are formally taught in class regarding the SDA concept for managing partially dentate patients and the extent to which clinical implementation of this treatment protocol actually occurs.

\section{Methods}

Ethical clearance (Registration No. 11/1/51) was obtained from the Research and Ethics Committee of the University of the Western Cape (UWC), South Africa. Written informed consent was obtained from the participants according to the Declaration of Helsinki. ${ }^{35} \mathrm{~A}$ mixed-methods approach was used in data collection (quantitative and qualitative) and analysis. ${ }^{36-38}$ Triangulation was used to eliminate bias and increase the validity and strengthen the reliability of the research..$^{37,38}$ The study drew on the sequential explanatory strategy in data collection and analysis and for subsequent inclusion of the semi-structured interview phases (qualitative data) following the completion of a survey (quantitative data). ${ }^{36-38}$

For the first phase, a survey was conducted amongst the senior dental students and their clinical teachers at UWC from January to March 2011 (survey is available from the corresponding author). The student sample was chosen because this group had completed the theory and related biomechanical principles of RPDs. ${ }^{37,38}$ Furthermore, their minimum clinical requirements included the completion of acrylic- and metal-based RPDs for patients with shortened, interrupted, or discontinuous arches.

The self-administered questionnaire was distributed and collected from the students and clinical faculty by the principal investigator (SK). The quantitative data (categorical and ordinal observations, as well as paired comparisons) were analyzed by a statistician using the Microsoft Excel statistical package. ${ }^{39}$ The categorical data were analyzed by 
means of residuals based on observed and expected values and using frequency distribution, Spearman rank correlations, and chi-squared statistics. ${ }^{39}$ The data were managed by dichotomization (definitely yes and yes, to a yes response), and this collapsed table strengthened the pattern of analysis. ${ }^{39}$

For the second and third phases of the study, qualitative interviews were conducted to supplement the findings from the survey. ${ }^{36,38}$ Smaller samples of students were selected for the semi-structured individual interviews $(\mathrm{n}=10)$ and for one semi-structured group interview ( $\mathrm{n}=1$, including ten students), both of which were conducted from April to June 2011..$^{36-38}$ These participating students were selected from the class $(n=73)$ via the process of statistical randomization accomplished through computer-generated numbers. ${ }^{37}$ The interviews permitted a more comprehensive discussion and understanding of why students were not suggesting or implementing the SDA as a treatment option. ${ }^{9,38}$

The semi-structured individual interviews with the students were of one-hour duration each, and responses were transcribed by the principal investigator (SK) ${ }^{36-38}$ Another group of ten senior dental students was also chosen by randomization for the semi-structured group interview. ${ }^{36-38}$ The Crawford slip-method allowed students to record their responses without any bias and avoid their being influenced by the thinking and responses of the group..$^{40,41}$ The use of this method allowed students to give their own independent opinions when answering the questions, and it ensured maximum participation from all students.

The qualitative data (semi-structured individual and group interviews) were analyzed using the analytical abstraction method (which has a clear, logical step-by-step analysis approach). ${ }^{38,42}$ Themes present in the literature review were used as a guide in the basic coding process. ${ }^{37,38,42}$ These themes include a discussion at the basic level (actual words of respondents) and a higher level (inferences of responses). The recorded text from both interviews used in the analysis ensured an accurate account of student responses, and member-checking was implemented in which students had to check that their responses were transcribed verbatim and were reflected in the subsequent interpretation. ${ }^{38}$

Furthermore, three emergent themes that became apparent from the basic analysis of the qualitative data were extrapolated; these themes are discussed in the results section..$^{37,38,42} \mathrm{~A}$ conceptual analysis of the data including an interpretation and discussion thereof is also presented. ${ }^{37,38}$ These strategies and sampling were included to increase the validity and strengthen the reliability of the research and at the same time reduce any bias encountered by the role of the researcher. ${ }^{37,38}$

\section{Results}

\section{Quantitative Data Analysis}

The quantitative data from the student and clinical teacher surveys are shown in Table 1. The response rates were 100 percent for the students $(n=73)$ and 78 percent for the clinical teachers $(n=16)$.

Student survey responses. Eleven percent of the student respondents indicated having heard about the SDA concept from this survey only and ascribed this omission to having missed lectures, not paying attention in class, or the lecturer placing little emphasis on this concept and without encouraging its use clinically. According to the Spearman rank correlation (0.565), a strong relationship existed between students' not having read the research (77 percent) and their lack of knowledge of the SDA variants (77 percent).

Many of the students indicated their proposed treatment for a SDA would include either metal (66 percent) or acrylic (53 percent) dentures or a combination of these with other treatment options such as implants (Table 1). Only 3 percent chose "no treatment" as a suggested treatment alternative for a patient with a SDA, which prompted extensive questioning in the interviews regarding their knowledge, classroom teaching, and clinical use of the SDA. Twelve percent of the respondents indicated "quota requirements" but 86 percent said "not having any knowledge" of the SDA will prevent their clinical use of this approach. More importantly, the students were totally unaware of the financial benefits for patients with the SDA treatment option. To the question of whether they would insist on making a denture for a clinical quota, 50 percent responded no. This response was unexpected as the students' main concern is the completion of minimum clinical requirements.

When we correlated the questions about "making of a denture for a quota" and "suggestions to implement the SDA as a treatment option," the distribution of the suggestions varied significantly $(p<0.05)$ : these significant differences were observed with the responses of "no suggestion" versus a "quota change." Nineteen percent of the students responded 
Table 1. Responses of students and teachers to survey regarding the shortened dental arch (SDA)

\begin{tabular}{|c|c|c|}
\hline Question & $\begin{array}{l}\text { Student Responses } \\
\qquad(\mathrm{n}=73)\end{array}$ & $\begin{array}{l}\text { Teacher Responses } \\
\qquad(\mathrm{n}=16)\end{array}$ \\
\hline 1. Where have you heard of the SDA? & $\begin{array}{l}81 \% \text { university } \\
11 \% \text { this survey }\end{array}$ & $\begin{array}{l}62 \% \text { university } \\
8 \% \text { this survey }\end{array}$ \\
\hline 2. Do you read SDA-related research? & $77 \%$ no/definitely no & $77 \%$ yes/definitely yes \\
\hline 3. Do you have knowledge of the variants of the SDA? & $77 \%$ no/definitely no & $77 \%$ yes/definitely yes \\
\hline 4. Can a patient function with an SDA? & $84 \%$ yes/definitely yes & $85 \%$ yes/definitely yes \\
\hline 5. Will you present SDA as a treatment option to patients? & $86 \%$ yes/definitely yes & $85 \%$ yes/definitely yes \\
\hline 6. Which treatment options will you propose to patients along with SDA? & $\begin{array}{l}66 \% \text { metal dentures } \\
53 \% \text { plastic dentures }\end{array}$ & $\begin{array}{l}69 \% \text { metal dentures } \\
38 \% \text { implants }\end{array}$ \\
\hline 7. What prevents you from presenting SDA to patients? & $86 \%$ lack of knowledge & $\begin{array}{l}16 \% \text { loss of income } \\
39 \% \text { other }\end{array}$ \\
\hline 8. How often do you advise patients not to replace missing molars? & $\begin{array}{l}41 \% \text { sometimes } \\
33 \% \text { rarely }\end{array}$ & $\begin{array}{l}62 \% \text { sometimes } \\
31 \% \text { rarely }\end{array}$ \\
\hline 9. How should SDA be implemented as a treatment option in the clinic? & $\begin{array}{l}51 \% \text { include SDA as a } \\
\text { clinical quota }\end{array}$ & $\begin{array}{l}\text { No suggestion/other } \\
\text { noncommittal } \\
\text { responses }\end{array}$ \\
\hline 10. Do you make dentures as a quota for the SDA patient? & $\begin{array}{l}50 \% \text { yes/definitely yes } \\
50 \% \text { no/definitely no }\end{array}$ & \\
\hline
\end{tabular}

"yes" and 39 percent responded "no" to the question of "no suggestion to the making of a denture for a quota" $\left(\chi^{2}=9.9627\right.$; d.f. $\left.=4 ; p=0.0411\right)$. Fifty-three percent of the students responded "yes" to a quota change (including the SDA) versus 19 percent who said "no" to a quota change.

Clinical teacher survey responses. The clinical teachers' responses indicated that they had read the research, knew about the SDA variants, and agreed that patients can function with a SDA (Table 1). However, their responses were of some concern as these clinical teachers nevertheless indicated that they would replace molars in all patients with a SDA. The disparity between knowing theoretical concepts and carrying out clinical implementation was obvious. Moreover, it can be assumed, though only speculated from this finding, that their teaching about and implementation of evidence-based findings were also absent.

\section{Qualitative Data Analysis}

The qualitative findings explain what happened during lectures and clinical implementation from the students' point of view. These are reported under three broad categories: basic and higher levels and then conceptual analysis of these two levels. The basic and higher levels are reported in themes-first, guided by the literature and then, second, those that became apparent after the analysis.

Basic and higher level analysis. The themes guided by the literature include definition of the SDA concept, classroom and clinical instruction, and minimum clinical requirements. Student comments on the SDA concept used in class included "no term SDA" or "a term interchange" and "SDA was not used." The definition of the SDA given in class (and used for distal extension dentures include teeth up to the first molars) is very different from that cited in the literature, where it is described as a premolar-topremolar occlusion. ${ }^{19-21}$ In spite of the rather indistinct definition of the SDA concept, the students suggested that this SDA "be used if it is advantageous to" or "benefits patients." Many students suggested that a separate lecture be given for an alternative treatment option such as the SDA as they were unaware of the extensive research conducted and expressed the need to be informed.

The student respondents commented that the classroom teaching of the SDA included "no explanation when teaching the concept" and "the way it was mentioned we regarded it as insignificant." Because of this brief mentioning of the SDA, the students clearly considered the concept as unimportant and forgot about it. ${ }^{11,12}$ Thus, its use clinically by students on their own initiative can hardly be expected. In- 
stead, the clinical teacher needed to assume the role of reminding them about the appropriate use of the SDA rather than ignoring situations in which its use could have greatly benefited the patient. ${ }^{11,12}$ The students were very conscious of the difference between classroom and clinical teachings and expressed their dissatisfaction that "student-centred learning does not occur in the clinics." Students commented that "attitudes from classroom and clinical teachers regarding 'new' concepts guide their professional behaviours after graduation," so the updating of knowledge to include evidence-based research both in class and clinics is imperative and has been notably absent.

The students responded explicitly to questions on minimum clinical requirements. Several students said that "if a procedure is not a requirement" or "you don't need to do it, students will ignore it." The students did not consider the financial implications and/or benefits for a patient when contemplating extending an SDA with an RPD. When they were made aware of this, however, they regarded it as "good ethical and moral clinical practice." The guidance received by students from clinical teachers can either encourage or discourage them from implementing new procedures that are not a requirement. Any new concept that can be clinically implemented by students should be included as a clinical requirement for that module. The students' clinical requirements should thus also be reviewed regularly to include information from new research.

Emergent themes. With the analytical abstraction method, the coding process also highlighted several themes that added considerable value to the teaching and learning experiences important to the student respondents. Regarding the clinical outcomes theme, even though students are guided clinically by minimum clinical requirements, the absence of clinical outcomes as in module learning outcomes (prescribed by the curriculum and provided to students) is evident. The use of clinical outcomes would serve as a guide to both students and clinical teachers, ensuring the updating and alignment of clinical education.

The interprofessional education theme was defined as occasions when two or more professions learn from and about each other to improve collaboration and health outcomes. Following the student interviews, the role of dental technicians was highlighted, and students regard their role as equally important when wanting to implement new concepts. ${ }^{43}$ Their knowledge of the SDA concept and their input with regards to laboratory procedures will affect its implementation and thus need to be aligned with evidence-based research and clinical education. The lack of knowledge and subsequent practice related to the SDA concept has been duly documented.

Regarding the theme of interviews, both the group and individual interviews conducted with these senior dental students simultaneously served as a teaching and learning opportunity for the principal investigator and the students. What is otherwise assumed or even disregarded was revealed as important items of information in these interviews - namely, the methodologies employed in clinical teaching (or lack thereof) and their impact on student learning and the role of clinical teachers and the consequence of their input on students' clinical decision making. ${ }^{44}$ In addition, faculty development and research and their beneficial impact on students became evident.

Regarding the conceptual analysis theme, students commented that they were not inclined to do any extra reading when the impression was created (in class or clinics) that a concept was insignificant. This attitude when presenting students with evidencebased research is as important as interpretation by students in guiding their clinical decision making. Thus, instructors must emphasize the importance of clinical concepts, not merely teach how to implement them, to convince students that such practices should be followed. According to Strayhorn, when specific classroom teaching strategies were employed, the tendency for students to learn the content and then appropriately transfer this knowledge to clinical practice is enhanced. ${ }^{4}$ The students in our study also suggested a change in the minimum clinical requirements (emphasizing module review) and a change in health policies to include and implement the SDA treatment option. Doing so would make both students and clinical teachers more aware of the concept. ${ }^{17}$ This attitude of dental practitioners regarding new concepts was observed in a study by Lalloo et al., which concluded that the effortlessness in using old concepts (e.g., restoring and extending shortened dental arches) could not be altered without shifting the mindset and health care policies for professionals and institutions. ${ }^{17}$

\section{Discussion}

The aims of this study were consistent with the goals of the institution that emphasize attributes of citizenship and scholarship of learning, amongst others. Given that these goals are embedded in the 
stated outcomes of every module in the curriculum, the findings of the study suggest that use of the SDA approach is not in conformity. In particular, the barriers to more meaningful translation of evidence-based concepts that are taught in class and clinical settings seem to have been identified by the interviewed students. From this result, it seems the inclusion of best evidence in the classroom needs to be supported and reinforced during clinical instruction so as not only to improve students' basic knowledge but also to empower them to apply new procedures appropriately. ${ }^{1-3}$ Doing so would help students more confidently advise and educate patients, make informed clinical decisions, and deliver the most appropriate treatment to their patients. One student expressed the view that this research had created evidence, which could change the mindset of practitioners and dental students. ${ }^{1-3}$ A related matter is that students will be undertaking community service in mostly rural communities after graduation, and a thorough grasp of the SDA concept would add greatly to their decision making skills in those relatively underserved clinical environments.

Currently at our institution, classroom instruction has moved to one of student-centered learning, in which a range of teaching strategies to achieve conceptual learning is included. ${ }^{2,11}$ However, while classroom instruction emphasizes that students adopt a patient-centered and problem-oriented treatment planning approach clinically, ${ }^{1-3}$ responses in the interviews did not confirm that this was taking place. Had such a problem-oriented treatment approach been effectively adopted, the prosthetically non-interventional SDA approach would conceivably have been considered. Consequently, students would have been obliged to complete clinical procedures beyond their clinical requirements. ${ }^{3,19,20}$ Doing what is best for the patient, including taking into account their financial and functional circumstances, would also encourage ethical and moral clinical practices. , $^{3,14,19,20}$

In terms of the aims of this study, what dental students were formally taught in class regarding the SDA concept did not relate well to clinical implementation of this treatment protocol. ${ }^{44}$ Whether this was due to the influence of sessional clinical staff (that is, their lack of knowledge related to classroom instruction on the SDA) is not established, but its existence cannot be overlooked and clearly needs re-consideration. ${ }^{45}$ Hence, the limitation of this confounder should be acknowledged, and a study that compares outcomes with sessional versus full-time clinical staff is warranted.
Following both the survey and interviews, the students now appear to be more familiar with the lowcost SDA treatment option, including the restrictions to specific clinical situations for the underprivileged majority in South Africa. ${ }^{29,34}$ They realize that it needs to be presented to patients, permitting them to make decisions regarding their own treatment needs. The ethics of overtreatment or incurring exorbitant costs to patients can be addressed partially in this way. This resonates with the findings of Henzi et al., who argued that clinical treatment that enforces certain costly procedures is unethical. ${ }^{14}$

The SDA concept is not taught as a separate topic, which could be seen as another flaw in the module. The extensive clinical research available, including the positive attitude of clinicians regarding its benefits, justifies its inclusion in the module. ${ }^{15,18-34}$ Indeed, this finding only became evident after the qualitative research, and it might not have been observed had only quantitative research been conducted. More significantly, this research allowed reflection on the content of the module, clinical practices, and the choice and training of clinical teachers. The subsequent inclusion of the SDA concept as a separate lecture can be recommended as a step in the right direction. The importance of instilling self-reflection with respect to our teaching practices (classroom and clinical), which became evident in our study, is also encouraged to improve the students' learning environment. ${ }^{2}$ Moreover, for this revision to be effective, a change in the protocol for the clinical setting and institutional policies regarding SDA therapy surely needs to be considered.

\section{Conclusion}

The results of this study indicate the students were positive towards the SDA concept as a treatment option for certain partially dentate adult patients. However, their lack of related knowledge and the absence of encouragement in the clinic were seen as hindrances to its implementation. These were linked to the emphasis on the SDA during classroom instructions and the nature of clinical guidance and/ or instruction. In addition to this, the knowledge of the clinical teachers appears not to be aligned with formal classroom instruction. Given the extensive body of evidence on the functional efficacies of the SDA approach and the widespread need for low-cost prosthetic management strategies in South Africa, the case for a more purposeful alignment of the 
theory and its clinical practice would seem justified. Thus, faculty development with appropriate ethical standards for clinical teachers should be expanded.

The SDA has been included as a separate lecture in the module that covers advanced removable denture procedures. The inclusion of this qualitative therapeutic intervention as a minimum clinical requirement and the necessary policy changes within the institution cannot be overemphasized. The barriers (of which there are many) to translate this knowledge into clinical practice should be dealt with urgently. Furthermore, ensuring consistency from didactic classroom instruction to implementation in a clinical setting would certainly standardize the curriculum regarding SDA therapy. This would ensure that students are able to implement this beneficial concept and thus address the needs of many underprivileged communities in their country.

\section{Acknowledgments}

Grateful thanks are extended to Prof. Yusuf Osman, Dr. Theunis Kotze, and Miss Shamima Allie for their invaluable guidance, support, and assistance with this research; to the BChD V Class of 2011 for their cooperation, support, and encouragement during this research; and to the UWC Ethics and Research Committee for financial assistance required for completion of this project.

\section{REFERENCES}

1. Rolfe IE, Sanson-Fisher RW. Translating learning principles into practice: a new strategy for learning clinical skills. Med Educ 2002;36:345-52.

2. Biggs J. Teaching for quality learning at university. $4^{\text {th }}$ ed. London: Open University Press, 2004.

3. Bensing J. Bridging the gap: the separate worlds of evidence-based medicine and patient-centered medicine. Patient Educ Couns 2000;39:17-25.

4. Strayhorn TL. Engaging schools: fostering high school students' motivation to learn. Educ Review 2004:1-8.

5. McMillan WJ. Teaching for clinical reasoning: helping students make conceptual links. Med Teach 2010;32: 436-42.

6. McMillan W. Making the most of teaching at the chairside. Eur J Dent Educ 2011;15:63-8.

7. McMillan WJ. "Then you get a teacher": guidelines in excellent teaching. Med Teach 2007;29:209-18.

8. MacLellan E. Conceptual learning: the priority for higher education. Br J Educ Stud 2005;53:129-47.

9. McMillan W. Finding a method to analyze qualitative data: using a study of conceptual learning. J Dent Educ 2009;73(1):53-64.

10. Khan SB. Effect of active learning techniques on dental students: a South African case study. S Afr J Higher Educ 2011;25(3).
11. Billing D. Teaching for transfer of core/key skills in higher education: cognitive skills. Higher Educ 2007;53:483-516.

12. Taber K. The mismatch between assumed prior knowledge and the learner's conceptions: a typology of learning impediments. Educ Stud 2001;27:159-71.

13. Kreuger PM, Neutens J, Bienstock J, et al. To the point: reviews in medical education teaching techniques. Am J Obstet Gynecol 2004;191:408-11.

14. Henzi D, Davis E, Jasinevicius R, Hendricson W. North American dental students' perspectives about their clinical education. J Dent Educ 2006;70(3):361-77.

15. Sarita PT, Witter DJ, Kreulen CM, et al. Oral health status related to the shortened dental arch concept in Tanzania. Eur J Oral Sci 2007;115:265-74.

16. Hays R. Assessment in medical education: roles for clinical teachers. Clin Teach 2008;5:23-7.

17. Lalloo R, Myburgh NG, Hobdell MH. Dental caries, socioeconomic development, and national oral health policies. Int Dent J 1999;49:196-202.

18. Käyser AF. Shortened dental arches and oral function. J Oral Rehabil 1981;8:457-62.

19. Omar R. Reappraising prosthodontic treatment goals for older, partially dentate people: Part II. Case for a sustainable dentition? SADJ 2004;59:228-37.

20. Käyser AF. The shortened dental arch: a therapeutic concept in reduced dentitions and certain high risk groups. Int J Periodontics Restorative Dent 1989;9:426-49.

21. Käyser AF, Witter DJ, Spanauf AJ. Overtreatment with removable partial dentures in shortened dental arches. Aust Dent J 1987;32(3):178-82.

22. Witter DJ, van Elteren P, Kayser AF. Signs and symptoms of mandibular dysfunction in shortened dental arches. J Oral Rehabil 1988;15:413-20.

23. Witter DJ, de Haan AF, Kayser AF, van Rossum GM. A 6-year follow-up study of oral function in shortened dental arches: Part I. occlusal stability. J Oral Rehabil 1994;21:113-25.

24. Allen PF, Witter DF, Wilson NHF, Käyser AF. Shortened dental arch therapy: views of consultants in restorative dentistry in the United Kingdom. J Oral Rehabil 1996;23:481-5.

25. Armellini DB, Von Fraunhofer JA. The shortened dental arch: a review of the literature. J Prosthet Dent 2004;92(6):531-5.

26. Baba K, Igarashi Y, Nishiyama A, et al. The relationship between missing occlusal units and oral health-related quality of life in patients with shortened dental arches. Int J Prosthodont 2008;21(1):72-4.

27. Ueno M, Yanagisawa T, Shinada K, et al. Masticatory ability and functional tooth units in Japanese adults. J Oral Rehabil 2008;35:337-44.

28. Zeng X, Sheiham A, Tsakos G. Relationship between clinical dental status and eating difficulty in an old Chinese population. J Oral Rehabil 2008;35:37-44.

29. Owen CP. Appropriatech: prosthodontics for the many, not just for the few. Int J Prosthodont 2004;17(2):261-2.

30. Sarita PT, Kreulen CM, Witter DJ, Creugers NH. Signs and symptoms associated with TMD in adults with shortened dental arches. Int J Prosthodont 2003;16:265-70.

31. Sarita PT, Witter DJ, Kreulen CM, et al. A study on occlusal stability in shortened dental arches. Int J Prosthodont 2003;16:375-80. 
32. Sarita PT, Witter DJ, Kreulen CM, Creugers NH. The shortened dental arch concept: attitudes of dentists in Tanzania. Community Dent Oral Epidemiol 2003;31:1115.

33. Sarita PT, Witter DJ, Kreulen CM, et al. Chewing ability of subjects with shortened dental arches. Community Dent Oral Epidemiol 2003;31:328-34.

34. Khan S, Chikte UME, Omar R. Perceptions regarding the shortened dental arch among dental practitioners in the Western Cape Province, South Africa. SADJ 2012;67(2):60-8.

35. World Medical Organization. Declaration of Helsinki. Br Med J 1996;313:1448-9.

36. Gill P, Stewart K, Treasure E, Chadwick B. Methods of data collection in qualitative research: interviews and focus groups. Br Dent J 2008;204:291-5.

37. Cohen L, Manion L, Morrison K. Research methods in education. $5^{\text {th }}$ ed. London: Taylor and Francis, 2005.

38. Creswell JW. Research design: qualitative, quantitative, and mixed methods approaches. $2^{\text {nd }}$ ed. Thousand Oaks, CA: Sage Publications, 2003.
39. Dawson B, Trapp RG. Basic and clinical biostatistics. $4^{\text {th }}$ ed. New York: McGraw-Hill, 2004.

40. Referencing pages in Principia Cybernetica Web. 2000. At: http://cleamc11.vub.ac.be/Heylighen. Accessed: April 17, 2013.

41. Straker D, Rawlinson G. How to invent (almost) anything. London: Spiro Press, 2003.

42. Crafford S, Bitzer E. Consumer learning for university students: a case for curriculum. Higher Educ Res Dev 2009;28:443-55.

43. Interprofessional Education Collaborative Expert Panel. Core competencies for interprofessional collaborative practice. Washington, DC: Interprofessional Education Collaborative, 2011.

44. Straus SE, Tetroe MA, Graham I. Defining knowledge translation. CMAJ 2009;181(3-4):165-8.

45. Fluit CRMG, Bolhuis S, Grol R, et al. Assessing the quality of clinical teachers. J Gen Int Med 2010;25(12): 1337-45. 